\title{
VIOLÊNCIA, DOMINAÇÃO E IDENTIDADE NACIONAL A PARTIR DO ESPAÇO AMBÍGUO EM GRANDE SERTÃO: VEREDAS
}

\section{VIOLENCE, DOMINATION, AND NATIONAL IDENTITY BASED ON THE AMBIGUOUS SPACE IN THE BOOK GRANDE SERTÃO: VEREDAS}

Fernanda Bezerra de Aragão Correia*

Sirley Almeida Adelino Baião**

Stephen Francis Ferrari***

Resumo: O presente artigo toma como base o espaço físico na obra Grande Sertão: Veredas, de Guimarães Rosa e visa investigar a problemática da violência e do poder, partindo da óptica do narrador Riobaldo, que constrói um sertão contraditório. É nessa esfera que barbárie e dominação produzem o coronelismo e o jaguncismo, frutos de uma situação colonial, de uma cultura europeia imposta e uma identidade negada. Com isso, configura-se um binário na sociedade patriarcal: o escravo e o dono da terra. A partir dessa estrutura, o sertão será lido sob a perspectiva teórica de Willi Bolle como alegoria do Brasil e reflexo do sistema político, econômico e social, lendo uma parte para compreender o todo, articulando transformações culturais e realidade brasileira por meio do pensamento sociológico da década 1930.

Palavras-chave: Espaço ambíguo. Violência. Jaguncismo. Colonização. Cultura.

\begin{abstract}
The present study is based on the concept of physical space in Grande Sertão: Veredas (The Devil to pay in the Backlands), the seminal work of Guimarães Rosa, and investigates the problem of physical violence from the viewpoint of the narrator, Riobaldo, who constructs a contradictory landscape. In this scenario, barbarianism and domination produce a feudal system and hired assassins, products of the impositions of the European colonial culture and a denied identity. This reflects the
\end{abstract}

\footnotetext{
"Mestre em Desenvolvimento e Meio Ambiente pelo PRODEMA (UFS). Licenciada em Letras Vernáculas pela Universidade Tiradentes. Email: fernanda_aragao@yahoo.com.br.

** Doutoranda em Desenvolvimento e Meio Ambiente-Universidade Federal do Sergipe. Email: enlluarada@hotmail.com

**** Professor adjunto da Universidade Federal de Sergipe e pesquisador do CNPq. Email: prof.stephenff@gmail.com.
} 
binary nature of the patriarchal society - the slave and the landowner. Based on this structure, the backlands are read through the theoretical perspective of Willi Bolle as an allegory of Brazil and its political, economic, and social systems, providing an alternative understanding of the country's social and cultural transformations from the perspective of the sociological thought of the 1930 .

Keywords: Ambiguous space. Violence. Hired assassins. Colonization. Culture.

INTRODUÇÃO

O homem representa o espaço que habita porque este o convida à ação para que, assim, possa transformá-lo. Pensar nas singularidades do espaço é ir além da ideia de espaço como geografia, superar o determinismo e partir para a intimidade dos espaços vividos, mergulhar na oniricidade espacial (BACHELARD, 1993). Sob essa ótica é que se pode observar as configurações do espaço, "tanto configurações sociais - o chamado espaço social - quanto configurações psíquicas - o chamado espaço psicológico" (SANTOS; OLIVEIRA, 2001, p.79). Se o espaço é imenso e profundo é porque a imensidão também está em nós. De acordo com a célebre reflexão do filósofo Gaston Bachelard (1993, p.190): “a imensidão é o movimento do homem imóvel". Conclui o filósofo que o espaço é um "horrível exterior-interior" (BACHELARD, 1993, p.221).

O real transcende. É no íntimo do ser, na imaginação poética subjetiva que se capta o espaço poético, gerando imagens poéticas, em meio a seus silêncios. E é preciso ler esses espaços poéticos, os silêncios e as infinitudes do real, semioticamente falando (PIGNATARI, 2004). Nessa transcendência, mediada por imaginação e imagens, o ho- mem é o meio e o meio é o homem - duplo processo.

A partir desse processo é que tomamos como objeto de análise o sertão na obra seminal de Guimarães Rosa (2001), Grande Sertão: Veredas, investigando suas ambiguidades e profundidades. Tudo é o sertão, todos nós somos um pouco do personagem Riobaldo, um pouco sertão. A ideia de ambiguidade espacial é construída pelo (pseudo) discurso do narrador, que dá voz à cultura, que tece uma linguagem simbólica e apresenta as dualidades entre rural/urbano, dentro/fora - os próprios "dois pontos" do título da obra representam dualidades, fronteiras, bem como o personagem Diadorim se faz ambíguo, andrógino.

Partimos aqui para uma revisitação do espaço sertanejo em tempos de globalização na literatura rosiana a partir das hipóteses da violência inerentes a uma República Velha que configurou o coronelismo numa sociedade patriarcal, antes de tudo numa nação de identidade forjada dos ocupados pelos ocupantes. É pela Estética da Violência (ROCHA, 2004) que chegamos ao jagunço como um "tipo especial de homem" (CANDIDO, 1970, p.148), que substitui o indígena e torna-se um "símbolo da brasilidade” (LIMA, 1999, p.64). Riobaldo, o jagunço letrado sui generis, traz consigo as marcas da valorização e "metropolização" do sertão 
para constituí-lo como nacionalidade, assim como representa os quatro séculos de escravidão e atraso da emancipação efetiva do país (BOLLE, 2004). Deixa de ser regional para ser universal.

\section{A AMBIGUIDADE NO SERTÃo ROSIANO}

A literatura regional de 1930, na denúncia do social, traçou um sertão de escassez, um sertão rude, de fome. Os personagens não tinham cosmicidade com seu espaço habitado. Esse mesmo sertão de fome da década 1930 foi filmado nos anos 1960 pelo Cinema Novo, principalmente em Glauber Rocha, ícone do movimento, para mostrar que a fome é nossa originalidade (ROCHA, 2004). Guimarães Rosa traz essa perspectiva contrapondo o atraso ao moderno, o litoral ao sertão, a civilização à barbárie, o rude ao belo (CANDIDO, 1978). Não há o desencadeamento de migração dos personagens para o centro urbano em Grande Sertão: Veredas como havia nos romances regionais de 30. Riobaldo é o sertão, luta e morre por ele. "O sertão a gente traz nos olhos, no sangue, nos cromossomos. É uma doença sem cura” (BRITO, 2008, p.19). Sertão é uno e múltiplo.

Sertão vai além de sua ideia de deserto, é polissêmico e está ligado ao pensamento cultural brasileiro. A obra de Guimarães também vai além do mito do sertanejo macho rústico e sofrido. Riobaldo confessa que já nasceu gostando do sertão. Por meio da aridez e da poesia da escrita rosiana, o sertão também é fantástico. "O sertão é do tamanho do mundo” (ROSA, 2001, p.89). Tudo é sertão. Sertão vasto. Riobaldo abre a narrativa com seu pronunciamento (2001, p. 23): "o senhor tolere, isto é o sertão". Por entre os fazendões de fazenda sem fim, o personagem descreve a fauna e flora:

Porque, nos gerais, a mesma raça de borboletas, que em outras partes é trivial regular - cá cresce, vira muito maior, e com mais brilho, se sabe; acho que é do seco do ar, do limpo, desta luz enorme. Beiras nascentes do Urucúia, ali o poví canta altinho. E tinha o xenxém, que tintipiava de manhã no revoredo, o saci-do-brejo, a doidinha, a gangorrinha, o tempo-quente, a rola-vaqueira... e o bem-te-vi que dizia, e araras enrouquecidas. Bom era ouvir o môm das vacas devendo seu leite. Mas, passarinho de bilo no desvéu da madrugada, para toda tristeza que o pensamento da gente quer, ele repergunta e finge resposta. Tal, de tarde, o bento-vieira, tresvoava, em vai sobre vem sob, rebicando de vôo todo bichinhozinho de finas azas; pássaro esperto. Ia de chover mais em mais tardinha que enche as árvores de cigarras - então, não chove. Assovios que fechavam o dia: o papa-banana, o azulejo, a garrincha-do-brejo, o suirirí, o sabiá-ponga, o grunhatá-do-coqueiro [...] (ROSA, 2001, p. 44).

No desenrolar da narrativa, o belo é representado mimeticamente pelos espaços naturais, rios, árvores, animais, o som dos bichos. Figura-se um alto grau de intimidade e valor onírico entre personagem e meio por uma linguagem poética que está presente na trama. Riobaldo consegue descrever a paisagem colorativa, como também 
tem afinidade com o rio Urucuia: "Olhe: o rio Carinhanha é preto, o Paracatú moreno; meu, em belo, é o Urucuia - paz das águas... é vida!" (ROSA, 2001, p. 43). Evidencia-se que o próprio nome do personagem possui a etimologia rio + baldo (rio: curso de água natural que se desloca de nível mais alto para o mais baixo aumentando progressivamente até desaguar no mar; baldo: barragem para represar as águas de um açude). Para ele, água é um símbolo de paz e felicidade, traz tranquilidade. "Perto de muita água, tudo é feliz” (ROSA, 2001, p. 45). A paisagem espacial é ambivalente e se compara a um rio belo, quando está fluente, e rude, quando está seco. Depende das ações dos personagens, influenciam os mesmos como também estes o influenciam. A fauna transcrita pelo narrador está transfigurada de certo encanto, pois ele está pensando em Diadorim.

Durante uma cena de batalha os personagens, rumo ao Liso do Sussuarão, sofridos devido ao mau tempo, decidem recuar no percurso.

A calamidade de quente! E o esbraseado, o estufo, a dor do calor e todos os corpos que a gente tem. Os cavalos venteando - só se ouvia o resfol deles, cavalanços e o trabalho custoso de suas passadas. Nem menos sinal de sombra. Água não havia. Capim não havia. A de beber os cavalos em cocho armado de couro, e dosar a meio, eles esticando os pescoços para pedir, eles olhavam como para seus cascos, mostrando tudo o que cangavam de esforço, e cada restar de bebida carecia de ser poupado. Se ia, o pesadêlo. Pesadêlo mesmo, de delírios. Os cavalos gemiam descrença. Já pouco forneciam. E nós estávamos perdidos. Nem um pôço não se achava. (ROSA, 2001, p. 67).
Mesmo com a seca, Riobaldo permeia o espaço, adequando-se a ele, sertão castigador. $\mathrm{E}$ o calor que atinge o sertão atinge também o íntimo do personagem. "O sol encostava na nuca da gente. Sol, solão, debaixo eu suava, transpirava dos cabelos [...]. Então, eu atirava" (ROSA, 2001, p.228). A natureza, pois, tanto é exterior como interior (Cf. NUNES, 2007). Se o espaço se faz insuportável, Riobaldo alerta para desconfiar dele. "O senhor não creia na quietação do ar. Porque o sertão se sabe só por alto. Mas, ou ele ajuda, com enorme poder, ou é traiçoeiro muito desastroso" (ROSA, 2001, p.548).

\section{A CULTURA DA VIOLÊNCIA NO SERTÃO}

A peculiaridade do romance consiste na investigação da realidade como subordinação à consciência ou põe esta consciência em uma realidade fora dela (interior/ exterior), partindo da impressão à observação, com a intervenção da inteligência, violando as fronteiras do real (CANDIDO, 2004). As obras do século XVI até a semana de 1922 refletiram um modelo europeu, predominando um bom mocismo na literatura (SANTIAGO, 2000) que só foi superado com a violência estético-ideológica da antropofagia modernista. Esse reflexo do europeu se explica pela nossa condição de país colonizado. O colonizador que aqui chegou deparou com um ocupante que não lhe pareceu adequado e, por isso, foi preciso criar outro. Domina-se para negá-lo.

Não somos europeus nem americanos do norte, mas destituídos de uma cultura original, nada nos é estrangeiro, 
pois tudo o é. A penosa construção de nós mesmos se desenvolve na dialética rarefeita entre o não ser e o ser outro. (GOMES, 1996, p.90).

Essa edificante tese de Paulo Emilio Sales Gomes trata não só da admiração (e submissão) ao estrangeiro, fazendo-a "uma qualidade de coisa nossa" (HOLLANDA; GONÇALVES, 1990, p.34), como da dependência cinematográfica de um modelo norte-americano, na busca de um cinema nacional independente, de uma produção de filmes descolonizados. A descolonização, por exemplo, não se restringe apenas à ordem cinematográfica, mas é de uma ordem estética, política, econômica. Assim como o cinema na década 1960 tenta desmontar os padrões estético-ideológicos do estrangeiro, a literatura da semana de 22 os faz, e principalmente os romances de 30 , trazendo para a literatura não mais aquele bom mocismo, mas a fome, revelando o subdesenvolvimento do Terceiro Mundo (GOMES, 1996). A resposta para isso: a violência. Bem nos lembrou Glauber Rocha (2004, p.31): "a mais nobre manifestação cultural da fome é a violência”.

O colonizador afirma seus valores, impõe a ética para o colonizado que julga ser ausente de tais valores. O colonizador vem tornar-se o patrão da terra, injetando sua supremacia de valores do homem branco. "O colono alimenta a cólera do colonizado e sufoca-a. O colonizado está preso nas malhas apertadas do colonialismo" (FANON, 1979, p.40). Já a descolonização se faz pelo confronto, em busca da liberdade do sistema colonial imposto. Fabrica novos homens. E os novos homens irão arquitetar modos de como aniquilar o colonizador. Assim, o sistema colonial fabrica a violência.

\begin{abstract}
A violência do colonizado, já o dissemos, unifica o povo. Por sua própria estrutura, com efeito, o colonialismo é separatista e regionalista. Não contente de constatar a existência de tribos, o colonialismo reforça-as, diferencia-as. O sistema colonial nutre as chefias e reativa as velhas confrarias marabúticas. A violência em sua prática é totalizante, nacional. (FANON, 1979, p.73-74).
\end{abstract}

Ainda há um caminho a percorrer: a busca para uma libertação nacional, elaborar uma identidade diferente da existente do dominador, destruir as categorias branco/negro, oprimido/opressor.

Analisar o Brasil dentro de uma visão do parasitismo social significa considerá-lo na sua inter-relação com a metrópole portuguesa. No entanto, na medida em que o colonizado é educado pelo colonizador, tem-se que aquele procura imitá-lo. As mazelas do "animal" parasita se transmitem, assim, hereditariamente para o parasitado. (ORTIZ, 1998, p.25).

O sertão "é onde manda quem é forte, com as astúcias. Deus mesmo, quando vier, que venha armado" (ROSA, 2001, p.35). Assim, o narrador descreve sua saga junto de Diadorim, sob o comando de Medeiro Vaz contra Hermógenes, num cenário de sangue derramado e paisagens 
contrastantes. As áreas rurais, onde a lei não se faz rígida como nos centros urbanos, já que no sertão manda quem é forte, são marcadas por violência e luta, comum também em outros espaços. No chapadão, o jagunço, homem meio desistido por si, segundo Riobaldo, faz justiça, mantém as regras, uma espécie de bandido social. E o personagem repete por várias vezes na diegese: viver é muito perigoso; com essa frase, o narrador adentra em suas angústias existenciais. Sobre isso, todos nós leitores nos identificamos com o personagem, "todos nós somos Riobaldo, que transcende o cunho particular do documento para encarnar os problemas comuns da nossa humanidade, num sertão que é também o nosso espaço de vida" (CANDIDO, 1970, p.151). Viver em si é muito perigoso, não só no campo como na cidade.

A violência que se alastra no bando de Riobaldo: "Sô Candelário? Morto em tiroteio de combate, metralhadoras tinham serrado o corpo dele, de esguêlha, por riba da cintura" (ROSA, 2001, p. 82). Violência que também se apresenta de forma mística, atribuindo a pessoas que vieram do inferno.

[...] as ruindades de regra que executavam em tantos pobrezinhos arraiais: baleando, esfaqueando, estripando, furando os olhos, cortando línguas e orelhas, não economizando crianças pequenas, atirando na inocência do gado, queimando pessoas ainda meio vivas, na beira de estrago de sangues... Esses não vieram do inferno? Saudações. (ROSA, 2001, p.65).
A problemática da violência, inserida no cenário da globalização do capitalismo, pôs em curso revoluções no limiar do século XX. Em suma, partindo da ideia da destruição do outro, "o mercantilismo, o colonialismo, o imperialismo e o globalismo podem ser vistos inclusive como processos histórico-sociais, ou geo-históricos, nos quais florescem as mais diversas formas e técnicas de violência" (IANNI, 2004, p.171). Nessa linha sociológica, Ianni (2004) percorre a sociedade capitalista como fábrica complexa que, ao passo que desenvolve a cooperação, fabrica a desigualdade, a fome e a violência.

Na sociedade escravocrata e patriarcal, sob a ótica sociológica de Gilberto Freyre (2002), o contato do senhor da casa com o escravo gerava sempre degradação e depravação. "Não há escravidão sem depravação sexual. É da essência mesma do regime" (FREYRE, 2000, p.423). Os negros que vinham ao Brasil não eram negros quaisquer dos canaviais, vinham negras para satisfazer o homem da casa-grande, negros que entendiam de comércio, de criação de gado. A violência pela qual o negro passou constituiu-se física, pois o negro, dentre vários outros aspectos, foi vítima da sífilis, contaminados pelos rapazes brancos da casa-grande que abusavam das negras (muitas vezes virgens). A sífilis e a gonorreia se espalharam pelo Brasil patriarcal, "terra da sífilis por excelência” (FREYRE, 2000, p.425).

Todos esses acontecimentos no sertão, sob a perspectiva do crítico Willi Bolle (2004), fazem um retrato do Brasil, uma representação dos problemas políticos e sociais, um sertão que supera as suas dicotomias. 
Com isso, a explicação do país por meio de dicotômicas é superada por uma compreensão baseada numa dialética dos contrários, diagnosticada por Euclides, reelaborada por Sérgio Buarque e aperfeiçoada por Guimarães Rosa. [...] O sertão não é somente uma referência geográfica externa, mas igualmente um espaço interior, simbólico, e a narração é a sondagem desse espaço. (BOLLE, 2004, p. 314).

Grande Sertão: Veredas, além de "representar o imenso atraso para a emancipação efetiva do país" (BOLLE, 2004, p. 385), é um romance de formação que "apresenta a guerra no sertão através do prisma dos discursos, diferentemente de Euclides da Cunha que a narra como uma sequência de acontecimentos" (BOLLE, 2004, p. 117), em que Riobaldo é o jagunço senhor de terras, diferente dos moldes de Antonio Conselheiro.

\section{ConClusão}

O romance desencadeia os problemas da ordem/desordem no encontro do ocupado com o ocupante, do escravo com o senhor, do iletrado com o letrado, da civilização com o rural; desencadeia fatos sociais do país, tais como "cultura e rusticidade, [...] insuficiência dos costumes tradicionais, [...] imitação artificial do importado e ruptura com o velho" (RONCARI, 2004, p. 21). Nesse contexto, salienta-se a tese de "uma cultura capaz de se relacionar com a miséria e a violência" (BENTES, 2007, p. 249), de um romance que permite "montar um retrato do Brasil articulado pelo próprio povo"
(BOLLE, 2004, p.438) e que revisita os conceitos de povo e de nação. $\mathrm{O}$ "dilaceramento do narrador e seu modo despedaçado de narrar" (BOLLE, 2004, p.264) mostram a falta de diálogo entre as classes sociais brasileiras e, nesse curso, a violência parece intrínseca. Evidente ou escondida, no individual ou no coletivo, é a estética da violência, primordialmente, um fenômeno histórico. Ação, transformação e luta para construir a identidade nacional.

\section{REFERÊNCIAS}

BACHELARD, G. Poética do espaço. São Paulo: Martins Fontes, 2008.

BENTES, I. Sertões e favelas no cinema brasileiro contemporâneo: estética e cosmética da fome. Revista ALCEU, v.8, n.15, p.242-255, jul./dez. 2007.

BOLLE, W. Grandesertão.br: o romance de formação do Brasil. São Paulo: Duas Cidades, 2004

BRITO, R. C. de. Galiléia. Rio de Janeiro: Alfaguara, 2008a.

CANDIDO, A. Tese e antítese: ensaios. São Paulo: Ed. Nacional, 1978.

Vários escritos. São Paulo: Duas

Cidades, 1970.

O observador literário. Rio de Janeiro:

Ouro sobre Azul, 2004.

FANON, F. Os condenados da terra. Rio de Janeiro: Civilização Brasileira, 1979.

FREYRE, G. Casa-grande \& senzala. In: SANTIAGO, S. (Coord.). Intérpretes do Brasil. Rio Janeiro: Nova Aguillar, v.3, 2000, p. 121-645 GOMES, P. E. S. Cinema: trajetória no subdesenvolvimento. São Paulo: Paz e Terra, 1996. 
HOLlANDA, H. B. de; GONÇALVES, M. A. Cultura e participação nos anos 60. São Paulo: Brasiliense, 1990.

IANNI, O. Capitalismo, violência, terrorismo. Rio de Janeiro: Civilização Brasileira, 2004. LIMA, N. T. Um sertão chamado Brasil: intelectuais e representação geográfica da identidade nacional. Rio de Janeiro: Revan: IUPERJ, UCAN, 1999.

NUNES, B. Bichos, plantas e malucos no sertão rosiano. In: SECCHIN, A. C. et al. (Orgs.). Veredas no sertão rosiano. Rio de Janeiro: 7letras, 2007.

ORTIZ, R. Cultura brasileira e identidade nacional. São Paulo: Brasiliense. 1985.

PIGNATARI, D. Semiótica \& literatura. São Paulo: Ateliê Editorial, 2004.
ROCHA, G. Revolução do cinema novo. Rio de Janeiro: Alhambra/Embrafilme, 1980. RONCARI, L. O Brasil de rosa (mito e história no universo rosiano): o amor e o poder. São Paulo: Editora UNESP, 2004.

ROSA, J. G. Grande sertão: Veredas. Rio de Janeiro: Nova Fronteira, 2001.

SANTIAGO, S. Uma literatura nos trópicos: ensaios sobre dependência cultural. Rio de Janeiro: Rocco, 2000.

- Nas malhas da letra: ensaios. Rio de Janeiro: Rocco, 2002.

SANTOS, L. A. B.; OLIVEIRA, S. P. Sujeito, tempo e espaço ficcionais: introdução à teoria da literatura. São Paulo: Martins Fontes, 2001.

Recebido para publicação 30 maio 2013 Aceito para publicação 30 set. 2013 